\title{
Time-Dependent Vascular Effects of Endocannabinoids Mediated by Peroxisome Proliferator-Activated Receptor Gamma (PPAR $\gamma$ )
}

\author{
Saoirse E. O'Sullivan, ${ }^{1}$ David A. Kendall, ${ }^{2}$ and Michael D. Randall ${ }^{2}$ \\ ${ }^{1}$ School of Graduate Entry Medicine and Health, Derby City General Hospital, University of Nottingham, Derby DE22 3DT, UK \\ ${ }^{2}$ School of Biomedical Sciences, Queen's Medical Centre, University of Nottingham, Nottingham NG7 2UH, UK \\ Correspondence should be addressed to Saoirse E. O’Sullivan, saoirse.o’sullivan@nottingham.ac.uk
}

Received 9 December 2008; Accepted 5 February 2009

Recommended by Antonio Brunetti

The aim of the present study was to examine whether endocannabinoids cause PPAR $\gamma$-mediated vascular actions. Functional vascular studies were carried out in rat aortae. Anandamide and N-arachidonoyl-dopamine (NADA), but not palmitoylethanolamide, caused significant vasorelaxation over time ( 2 hours). Vasorelaxation to NADA, but not anandamide, was inhibited by $\mathrm{CB}_{1}$ receptor antagonism (AM251, $1 \mu \mathrm{M}$ ), and vasorelaxation to both anandamide and NADA was inhibited by PPAR $\gamma$ antagonism (GW9662, $1 \mu \mathrm{M})$. Pharmacological inhibition of de novo protein synthesis, nitric oxide synthase, and super oxide dismutase abolished the responses to anandamide and NADA. Removal of the endothelium partly inhibited the vasorelaxant responses to anandamide and NADA. Inhibition of fatty acid amide hydrolase (URB597, $1 \mu \mathrm{M}$ ) inhibited the vasorelaxant response to NADA, but not anandamide. These data indicate that endocannabinoids cause time-dependent, PPAR $\gamma$-mediated vasorelaxation. Activation of PPAR $\gamma$ in the vasculature may represent a novel mechanism by which endocannabinoids are involved in vascular regulation.

Copyright (C) 2009 Saoirse E. O'Sullivan et al. This is an open access article distributed under the Creative Commons Attribution License, which permits unrestricted use, distribution, and reproduction in any medium, provided the original work is properly cited.

\section{Introduction}

Peroxisome proliferator-activated receptors (PPARs) are nuclear receptors which control the transcription of many families of genes. They have a large ligand binding pocket and are pharmacologically promiscuous, being activated by a number of structurally diverse natural and synthetic ligands including some angiotensin II receptor antagonists [1], statins [2], retinoic receptor antagonists [3], flavinoids [4], and citrus fruit compounds [5]. An increasing body of evidence now also suggests that cannabinoids activate PPARs, and this may mediate some of the biological effects of cannabinoids [6], in addition to activation of two wellestablished 7-transmembrane cannabinoid receptors $\left(\mathrm{CB}_{1}\right.$ and $\mathrm{CB}_{2}$ ).

The first evidence of cannabinoid interactions with PPAR came in 2002 in a study by Kozak and colleagues who showed that lipoxygenase metabolism of the endocannabinoid, 2-arachidonoylglycerol (2-AG), produced a metabolite that increases the transcriptional activity of PPAR $\alpha$ [7]. Fu et al. (2003) then showed that the appetite-suppressing and weight-reducing effects of another endocannabinoidrelated agent, oleoylethanolamide (OEA), were absent in PPAR $\alpha$ knock-out mice [8]. Guzmán et al. (2004) also showed that the stimulatory effect of OEA on lipolysis in vivo was absent in PPAR $\alpha$ knock-out mice [9]. Palmitoylethanolamide (PEA), which is structurally related to OEA, similarly activates PPAR $\alpha$ transcriptional activity, causing anti-inflammatory actions that were absent in PPAR $\alpha$ knock-out mice [10]. Other endocannabinoids that have been shown to activate PPAR $\alpha$ include noladin ether and virodhamine [11].

As well as activating PPAR $\alpha$, it was shown in 2003 [12] that the synthetic cannabinoid, ajulemic acid (an analogue of a tetrahydrocannabinol metabolite) binds to and increases the transcriptional activity of PPAR $\gamma$. We have since shown that the principal active ingredient of Cannabis sativa, $\Delta^{9}$ tetrahydrocannabinol (THC), activates the transcriptional activity of PPAR $y$ and stimulates adipogenesis, a PPAR $\gamma$ property [13]. The endocannabinoids anandamide and 2-AG have anti-inflammatory effects which are sensitive to PPAR $\gamma$ antagonism $[14,15]$, although it was not clear whether these 
effects were through activation of PPAR $y$ directly, or via metabolites of the endocannabinoids. Subsequent research has shown that anandamide directly binds to PPAR $\gamma[16$, 17], activates PPAR $\gamma$ transcriptional activity, and stimulates the differentiation of fibroblasts to adipocytes [16]. Other cannabinoids that activate the transcriptional activity of PPAR $y$ include the endocannabinoid/endovanilloid, Narachidonoyl-dopamine (NADA), the synthetic cannabinoids WIN55212-2 and CP55940, and the phytocannabinoid, cannabidiol [18].

We have shown that THC causes time-dependent, endothelium-dependent, PPAR $\gamma$-mediated vasorelaxation of the rat isolated aorta [13]. This response was dependent on nitric oxide (NO) and superoxide dismutase (SOD) activity [13]. Furthermore, subsequent studies showed that 2-hour incubation with THC $(10 \mu \mathrm{M})$ in vitro blunts subsequent contractile responses and enhances vasodilator responses in isolated arteries, which was also inhibited by a PPAR $\gamma$ antagonist [19]. These experiments similarly indicated a role for increased SOD activity stimulated by THC. Together, these studies suggest that THC, through activation of PPAR $\gamma$, leads to increased synthesis of SOD, promoting vasorelaxation by preventing NO being scavenged by endogenous superoxides. This is in agreement with research showing that, in addition to direct effects on NO production, PPAR $\gamma$ ligands enhance NO bioavailability in blood vessels through induction of SOD [20].

There has been much interest surrounding the vascular actions of endocannabinoids. The mechanisms underpinning the acute vasorelaxant response to endocannabinoids include activation of sensory nerves [21-23], activation of the $\mathrm{CB}_{1}$ receptor, and activation of a novel endothelial cannabinoid receptor [23-25]. In light of the growing evidence that endocannabinoids activate PPAR $\gamma$ [14-18], the aim of the present study was to investigate whether similar time-dependent, PPAR $\gamma$-mediated vasorelaxation to endocannabinoids occurs in the rat aorta as observed for THC, and to investigate the underlying mechanisms.

\section{Material and Methods}

2.1. In Vitro Vascular Studies. Male Wistar rats (250-350 g) were stunned by a blow to the back of the head and killed by cervical dislocation. The aortae were removed rapidly and placed into cold modified Krebs-Henseleit buffer (composition, mM: $\mathrm{NaCl} 118, \mathrm{KCl} 4.7, \mathrm{MgSO}_{4}$ 1.2, $\mathrm{KH}_{2} \mathrm{PO}_{4}$ 1.2, $\mathrm{NaHCO}_{3} 25, \mathrm{CaCl}_{2}$ 2, and D-glucose 10). The aortae were dissected free of adherent connective and adipose tissue and cut into rings 3-4 $\mathrm{mm}$ long, and mounted on fixed segment support pins using the Multimyograph system (Model 610M, Danish Myo Technology, Denmark) as previously described $[13,19,23]$. Once mounted, all vessels were kept at $37^{\circ} \mathrm{C}$ in modified Krebs-Henseleit buffer and gassed with $5 \% \mathrm{CO}_{2}$ in $\mathrm{O}_{2}$. The aortae were stretched to an optimal passive tension of $9.8 \mathrm{mN}$ tension. Vessels were allowed to equilibrate and the contractile integrity of each was tested by its ability to contract to $60 \mathrm{mM} \mathrm{KCl}$ by at least $4.9 \mathrm{mN}$. Vessels were contracted with a combination

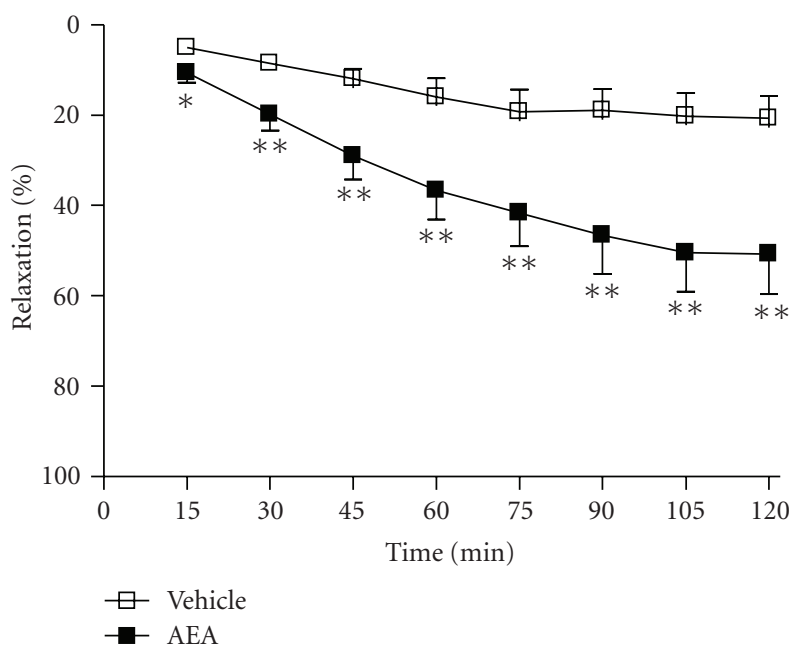

(a)

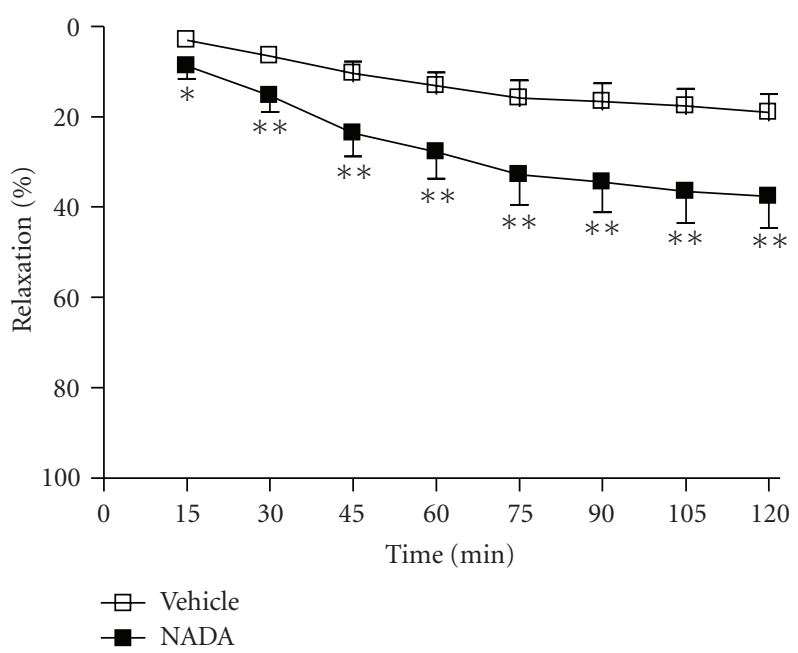

(b)

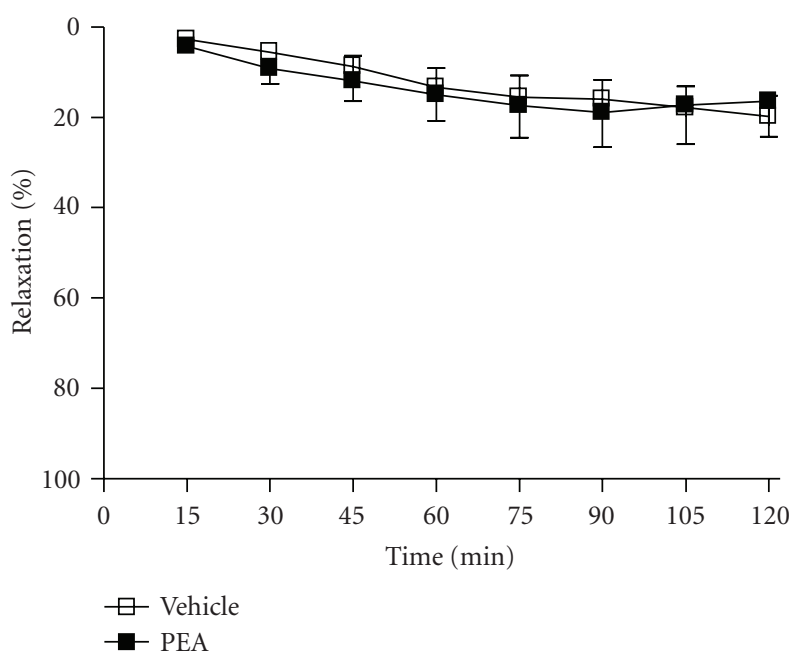

(c)

Figure 1: The mean vasorelaxant response to (a) AEA, (b) NADA, and (c) PEA versus vehicle $(0.1 \% \mathrm{EtOH})$ over 2 hours in preconstricted aortae. Data are given as means with error bars representing SEM. ( ${ }^{*} P<.05,{ }^{*} P<.01$, Student's $t$-test, $\left.n=12\right)$. 


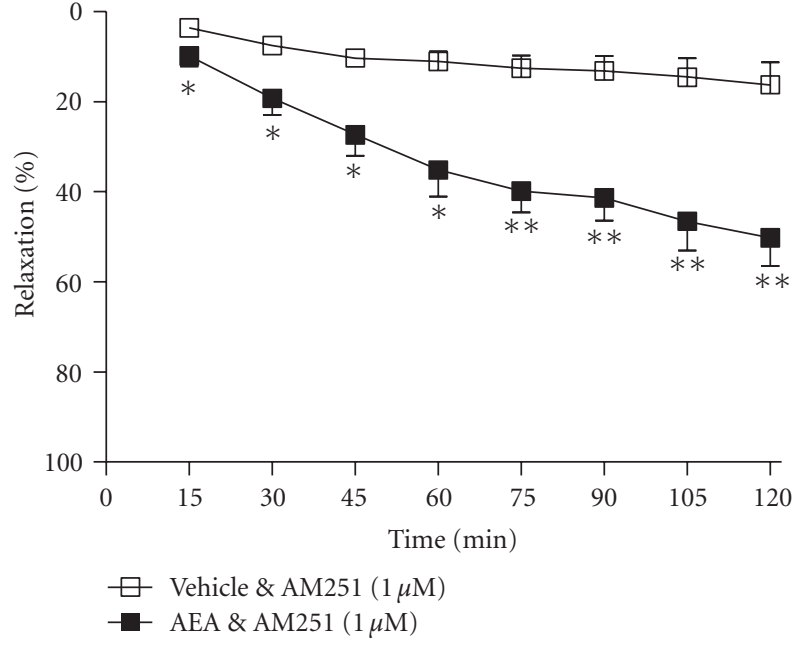

(a)

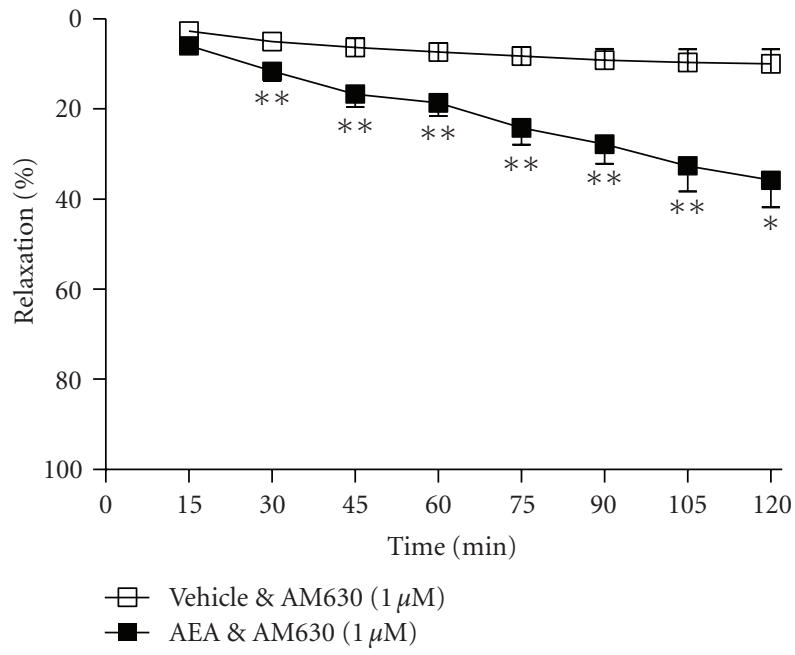

(c)

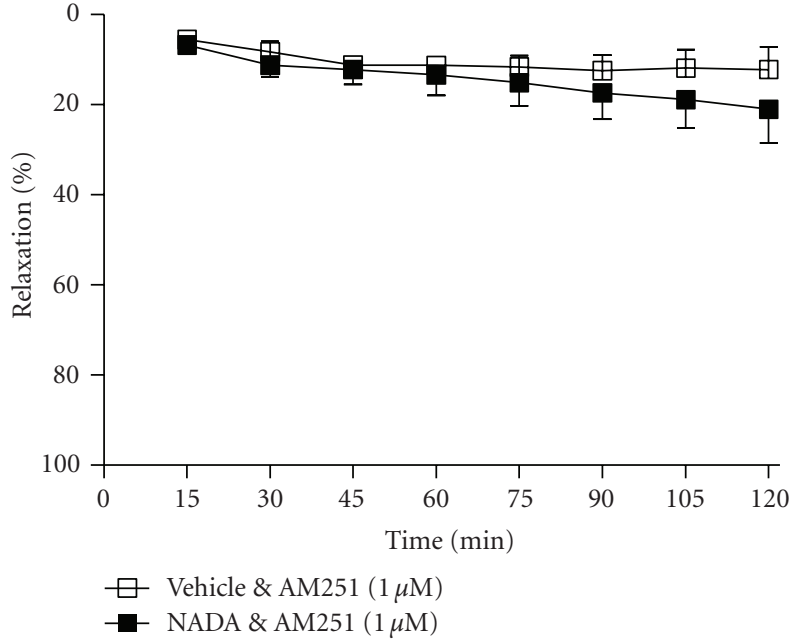

(b)

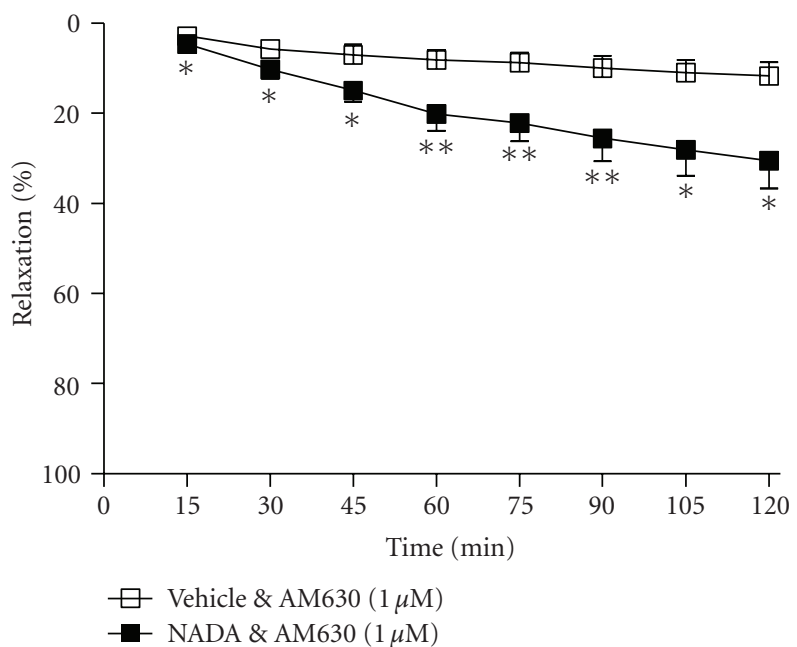

(d)

Figure 2: The effects of the $\mathrm{CB}_{1}$ receptor antagonist AM251 $\left(1 \mu \mathrm{M},(\mathrm{a})\right.$, and (b)) and the $\mathrm{CB}_{2}$ receptor antagonist $\mathrm{AM} 630(1 \mu \mathrm{M},(\mathrm{c})$, and (d)) on vasorelaxation to anandamide and NADA. Data are given as means with error bars representing SEM. $\left({ }^{*} P<.05,{ }^{* *} P<.01\right.$, Student's $t$-test.)

of U46619 (10-100 nM, a thromboxane prostanoid receptor agonist), and the $\alpha$-adrenoceptor agonist methoxamine (1$5 \mu \mathrm{M})$ to increase tension.

When stable contraction was maintained, the vasorelaxant effect of a single concentration of endocannabinoid or vehicle control $(0.1 \%$ ethanol) on induced tone was assessed as the reduction in tone over time. The endocannabinoids chosen were anandamide $(5 \mu \mathrm{M})$ and NADA $(10 \mu \mathrm{M})$, both previously demonstrated to be PPAR $\gamma$ ligands $[14,16-18]$, and PEA $(10 \mu \mathrm{M})$, which activates PPAR $\alpha$ but not PPAR $\gamma$ [10]. For every experimental protocol, vehicle-treated and endocannabinoid-treated experiments were performed in adjacent segments of the same artery.

To assess any possible contribution of vasorelaxation mediated through cannabinoid receptors, some experiments were performed in the presence of the cannabinoid $\mathrm{CB}_{1}$ receptor antagonist $\mathrm{AM} 251(1 \mu \mathrm{M})$, or the $\mathrm{CB}_{2}$ receptor antagonist AM630 $(1 \mu \mathrm{M})$, both added 10 minutes before contracting the vessels.

To assess the contribution of PPAR $\gamma$ activation, some experiments were performed in the presence of the PPAR $\gamma$ antagonist GW9662 $(1 \mu \mathrm{M})$ added 10 minutes prior to precontraction. To establish whether the time-dependent vasorelaxant effects of endocannabinoids were dependent upon de novo protein synthesis, some experiments were performed in the presence of the protein synthesis inhibitor cycloheximide $(10 \mu \mathrm{M})$.

To investigate the role of endothelium-derived relaxing factors in the time-dependent vasorelaxation to endocannabinoids, some vessels were denuded of their endothelium by abrasion with a human hair. The role of endothelium-derived nitric oxide (NO) was investigated using the $\mathrm{NO}$ synthase inhibitor $\mathrm{N}^{\mathrm{G}}$-nitro-L-arginine methyl ester (L-NAME, $300 \mu \mathrm{M}$, present throughout). To establish 


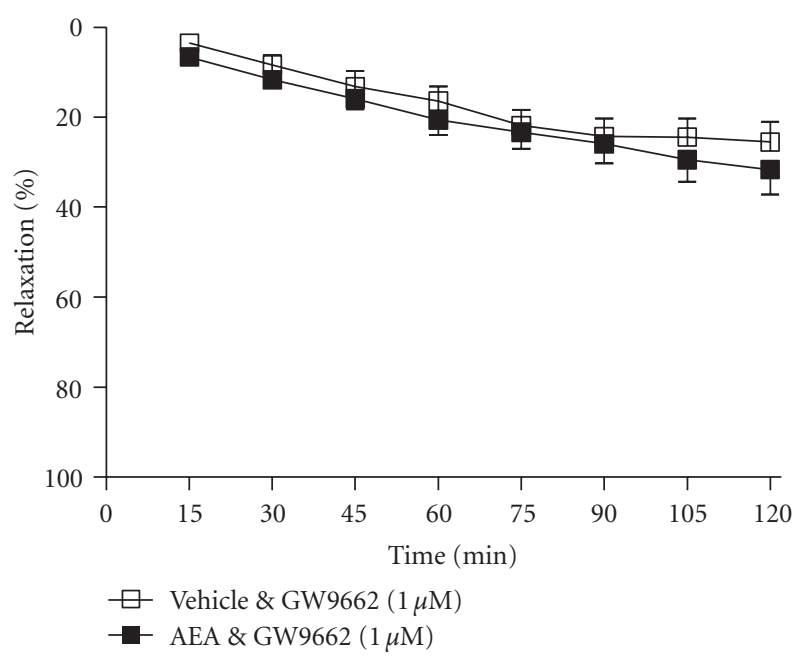

(a)

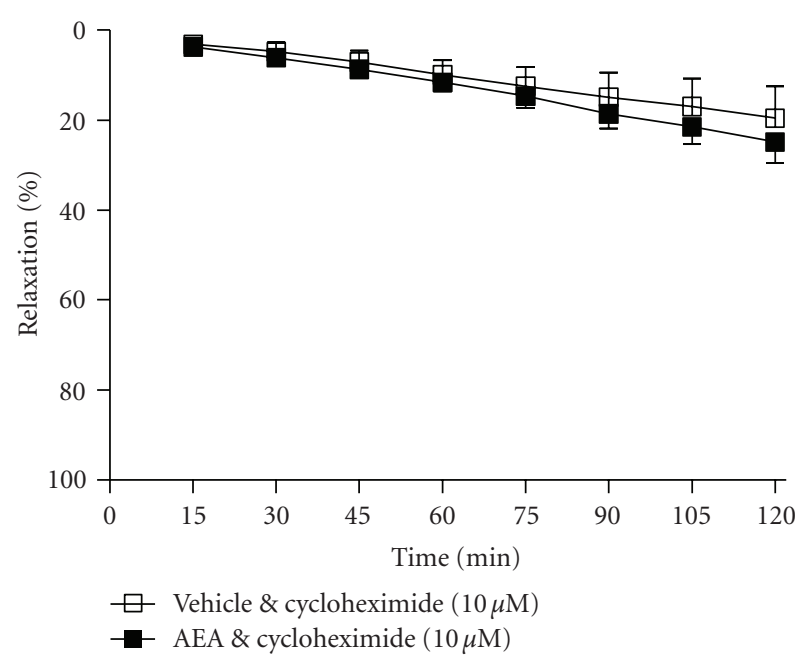

(c)

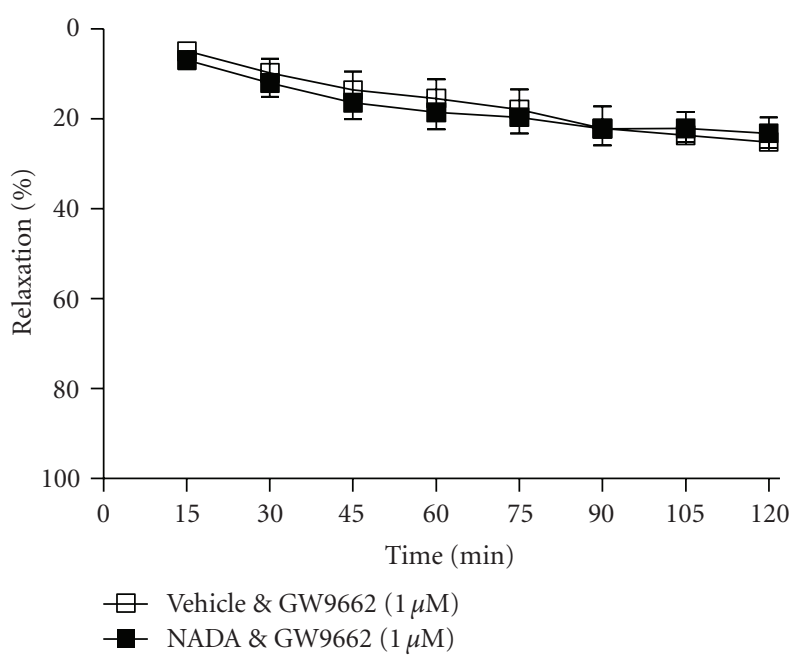

(b)

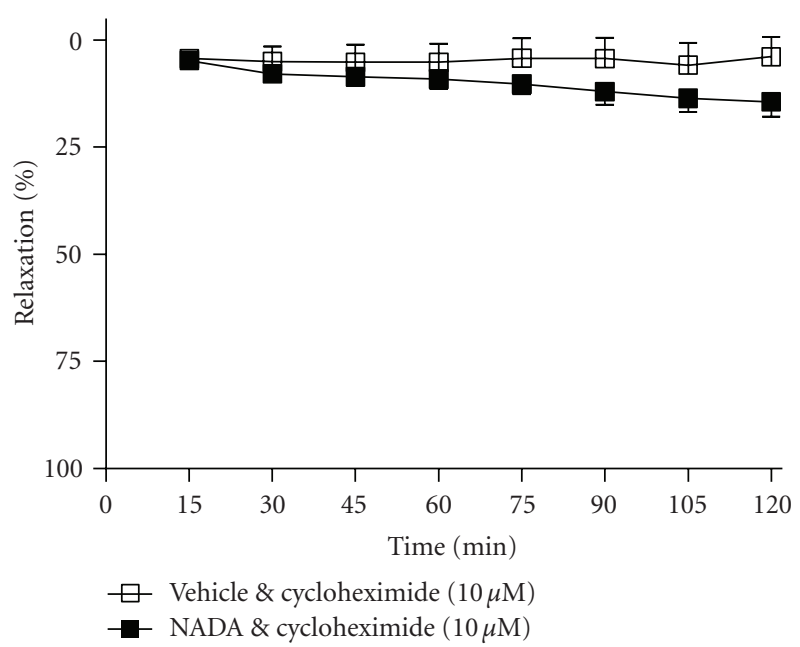

(d)

FIgure 3: The effects of the PPAR $\gamma$ antagonist GW9662 ( $1 \mu \mathrm{M}$, (a), and (b)) and the protein synthesis inhibitor, cycloheximide (10 $\mu \mathrm{M}$, (c), and $(\mathrm{d})$ ) on vasorelaxation to anandamide and NADA. Data are given as means with error bars representing SEM.

whether endocannabinoids cause increased expression of superoxide dismutase (SOD) activity, some experiments were performed in the presence of the SOD inhibitor diethyldithiocarbamate (DETCA, $3 \mathrm{mM}$ ), added 30 minutes prior to precontraction of arteries.

To assess whether the actions of endocannabinoids are due to their breakdown to other biologically active compounds that may act at PPAR $\gamma$, some vessels were treated with the FAAH inhibitor, URB597 $(1 \mu \mathrm{M}$, added 10 minutes prior to precontraction).

2.2. Statistical Analysis. In each protocol, the number of animals in each group is represented by $n$, and values are expressed as mean \pm SEM. The difference between endocannabinoid-treated and vehicle-treated vessels (adjacent segments from the same aorta) under each experimental protocol were analysed by paired Student's $t$-test.
2.3. Drugs. All drugs were supplied by Sigma Chemical Co. (UK) except where stated. Anandamide, NADA, PEA, AM251, AM630, and GW9662 were obtained from Tocris (UK). L-NAME, DETCA, and cycloheximide were dissolved in the Krebs-Henseleit solution. Anandamide, NADA, PEA, and URB597 were dissolved in ethanol at $10 \mathrm{mM}$ with further dilutions made in distilled water. AM251, AM630, and GW9662 were dissolved in DMSO to $10 \mathrm{mM}$, with further dilutions in distilled water.

\section{Results}

3.1. Time-Dependent Vasorelaxant Effects of Endocannabinoids. Anandamide $(5 \mu \mathrm{M})$ caused significant timedependent relaxation of the rat aorta compared to vehicletreated arteries at all time-points over the course of 2 hours ( 2 hours, vehicle $21 \pm 5 \%$ versus AEA $51 \pm 8 \%$ relaxation, 


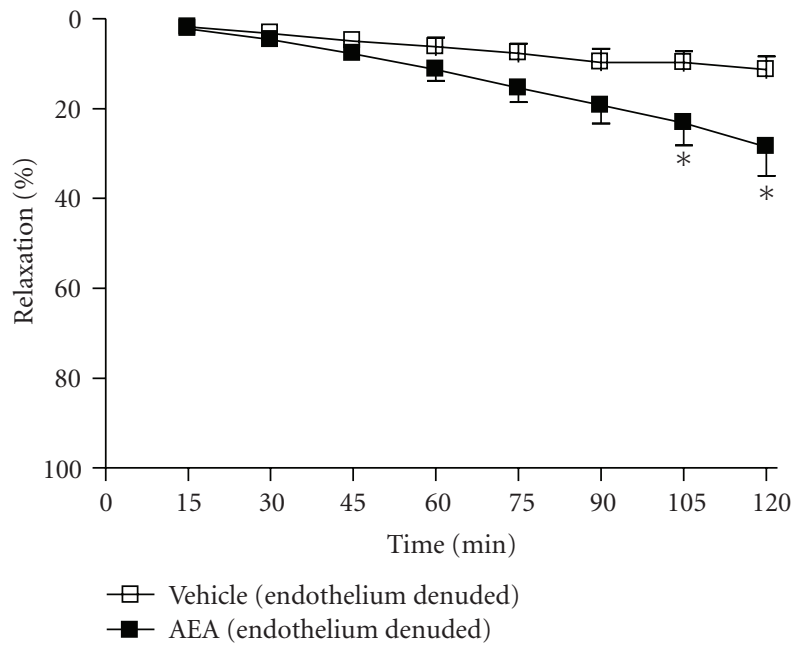

(a)

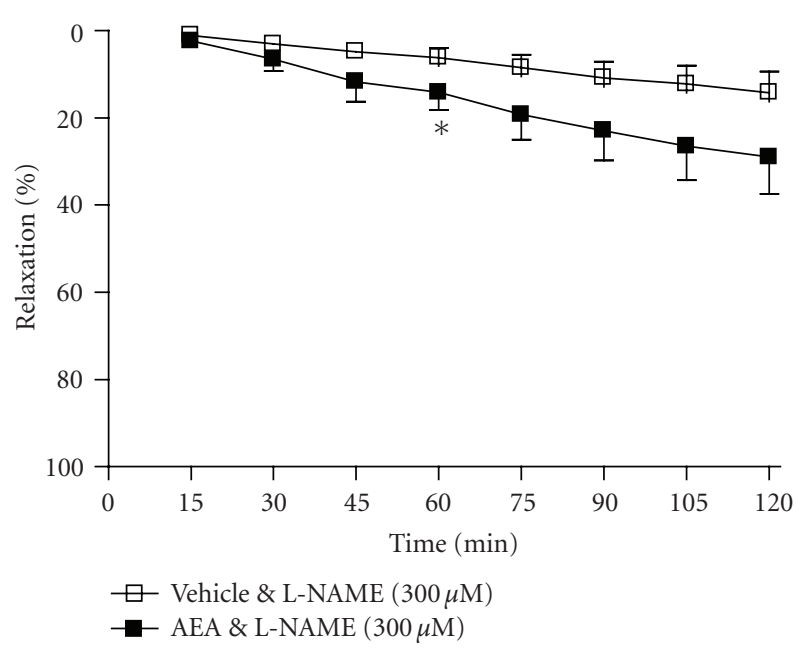

(c)

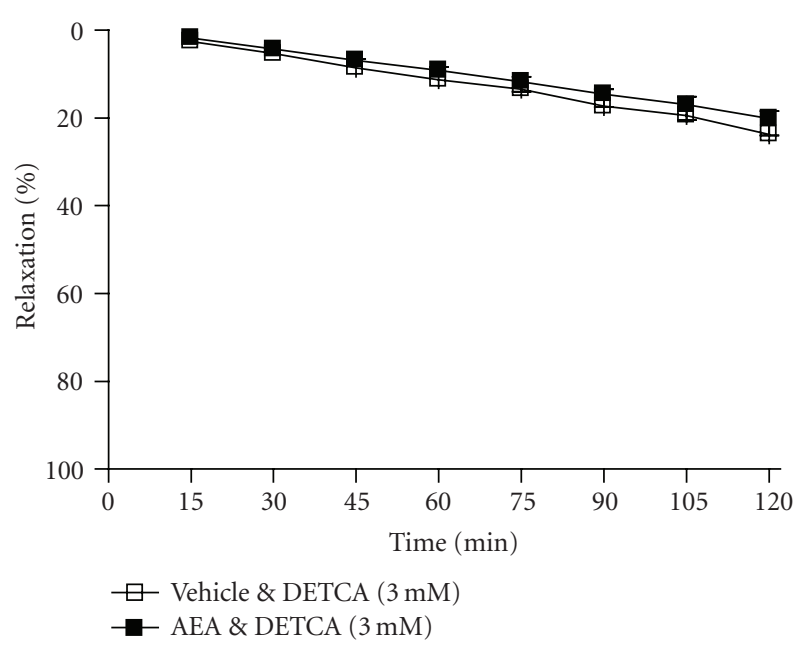

(e)

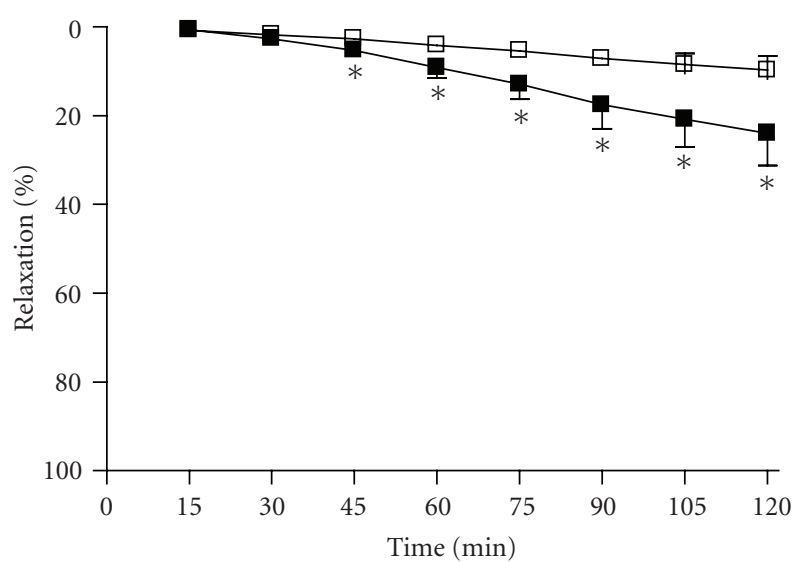

$\square$ Vehicle (endothelium denuded)

NADA (endothelium denuded)

(b)

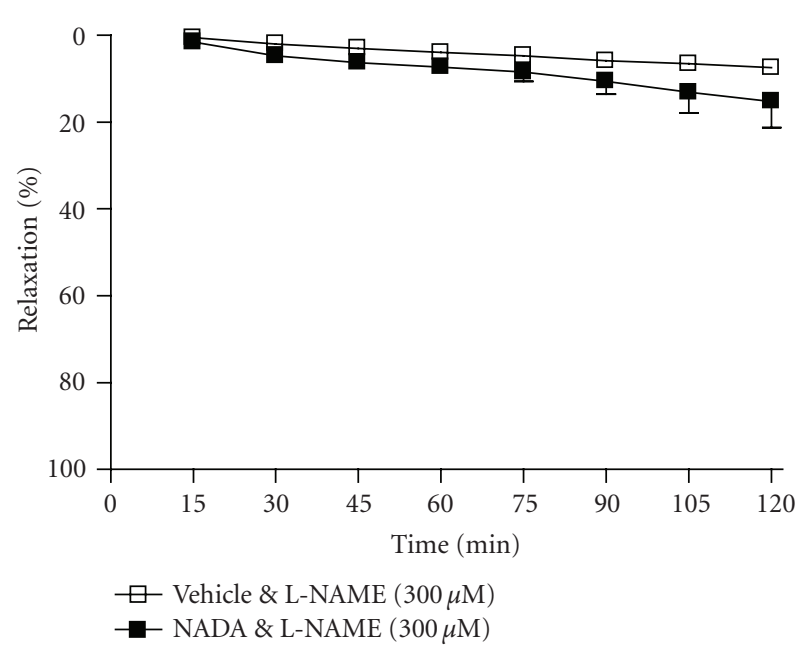

(d)

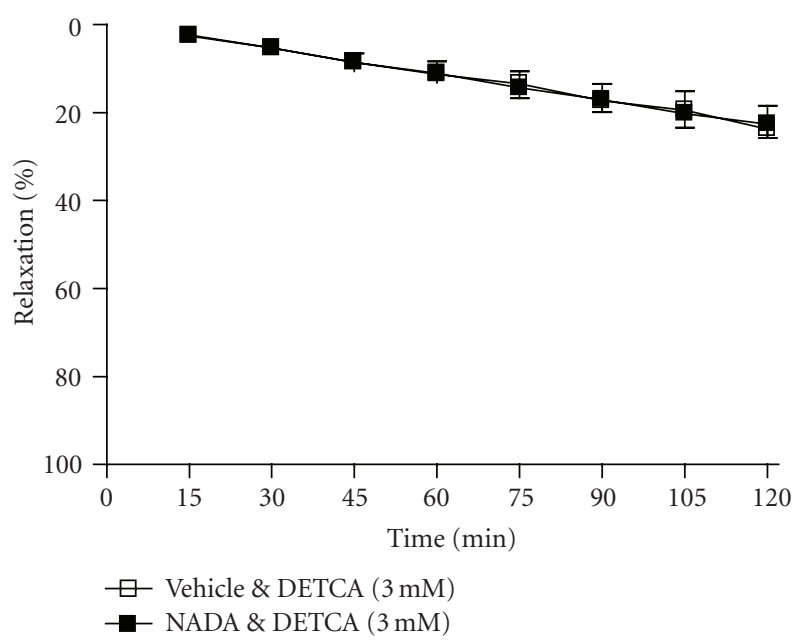

(f)

Figure 4: The effects of removing the endothelium ((a), (b)), inhibiting nitric oxide synthase (L-NAME, $300 \mu \mathrm{M}$, (c), and (d)), and inhibiting superoxide dismutase (DETCA, $3 \mathrm{mM}$, (e), and (f)) on vasorelaxation to anandamide and NADA. Data are given as means with error bars representing SEM. $\left({ }^{*} P<.05\right.$, Student's $t$-test $)$. 
$n=12, P<.01$, see Figure $1(\mathrm{a}))$. NADA $(10 \mu \mathrm{M})$ also caused significant time-dependent relaxation of the rat aorta compared to vehicle control at all time-points studied over the course of 2 hours ( 2 hours, vehicle $19 \pm 4 \%$ versus NADA $38 \pm 7 \%$ relaxation, $n=12, P<.01$, see Figure $1(\mathrm{~b})$ ). By contrast, PEA $(10 \mu \mathrm{M})$ did not have any significant effect on the rat aorta compared to vehicle (2 hours, vehicle $20 \pm$ $5 \%$ versus PEA $17 \pm 9 \%$ relaxation, $n=12$, Figure $1(\mathrm{c})$ ).

3.2. Receptor Sites of Action. In the presence of the cannabinoid $\mathrm{CB}_{1}$ receptor antagonist, AM251 $(1 \mu \mathrm{M})$, the vasorelaxant response to anandamide was not affected (2 hours, vehicle $16 \pm 4 \%$ versus AEA $50 \pm 5 \%$ relaxation, $n=9, P$ $<.01$, Figure 2(a)). By contrast, in the presence of AM251, the vasorelaxant response to NADA was abolished ( 2 hours, vehicle $12 \pm 4 \%$ versus NADA $21 \pm 6 \%$ relaxation, $n=$ 9, nonsignificant, Figure 2(b)). The $\mathrm{CB}_{2}$ receptor antagonist AM630 $(1 \mu \mathrm{M})$ did not affect the vasorelaxant response to either anandamide ( 2 hours, vehicle $10 \pm 3 \%$ versus AEA $36 \pm$ $5 \%$ relaxation, $n=9, P<.05$, Figure $2(\mathrm{c})$ ) or NADA ( 2 hours, vehicle $12 \pm 2 \%$ versus NADA $31 \pm 5 \%$ relaxation, $n=8, P$ $<.05$, Figure $2(\mathrm{~d}))$. In the presence of the PPAR $\gamma$ receptor antagonist GW9662 $(1 \mu \mathrm{M})$, the vasorelaxant effects of both anandamide ( 2 hours, vehicle $26 \pm 4 \%$ versus AEA $32 \pm 5 \%$ relaxation, $n=12$, nonsignificant, Figure $3(\mathrm{a})$ ) and NADA (2 hours, vehicle $25 \pm 4 \%$ versus NADA $23 \pm 3 \%$ relaxation, $n$ $=9$, nonsignificant, Figure 3(b)) were abolished.

3.3. Mechanisms of Action. In the presence of the protein synthesis inhibitor, cycloheximide $(10 \mu \mathrm{M})$, the vasorelaxant effects of both anandamide ( 2 hours, vehicle $20 \pm 6 \%$ versus AEA $25 \pm 4 \%$ relaxation, $n=8$, nonsignificant, Figure 3(c)) and NADA ( 2 hours, vehicle $4 \pm 4 \%$ versus NADA $14 \pm 3 \%$ relaxation, $n=9$, nonsignificant, Figure $3(\mathrm{~b})$ ) were abolished.

Removal of the endothelium limited the vasorelaxant effects of anandamide such that arteries treated with anandamide were significantly different from vehicle-treated arteries only at 105 and 120 minutes (2 hours, vehicle $11 \pm 3 \%$ versus AEA $29 \pm 6 \%$ relaxation, $n=11, P<$ .05 , see Figure $4(a))$. Similarly, removal of the endothelium limited the vasorelaxant response to NADA ( 2 hours, vehicle $10 \pm 3 \%$ versus AEA $24 \pm 6 \%$ relaxation, $n=9, P<.05$, see Figure $4(\mathrm{~b}))$. The NOS inhibitor, L-NAME $(300 \mu \mathrm{M})$, inhibited the vasorelaxant response to anandamide ( 2 hours, vehicle $16 \pm 5 \%$ versus AEA $31 \pm 8 \%$ relaxation, $n=11$, nonsignificant, Figure 4(c)) and NADA (2 hours, vehicle $6 \pm$ $1 \%$ versus NADA $15 \pm 5 \%$ relaxation, $n=8$, nonsignificant, Figure $4(\mathrm{c}))$. Similarly, the SOD inhibitor, DETCA $(3 \mathrm{mM})$ abolished the vasorelaxant response to both anandamide (2 hours, vehicle $20 \pm 4 \%$ versus AEA $20 \pm 8 \%$ relaxation, $n=8$, nonsignificant, Figure 4(e)) and NADA (2 hours, vehicle $24 \pm 4 \%$ versus NADA $22 \pm 3 \%$ relaxation, $n=8$, nonsignificant, Figure 4(f)).

3.4. Endocannabinoid Metabolism. The presence of the FAAH inhibitor, URB597 $(1 \mu \mathrm{M})$ did not affect the vasorelaxant effect of anandamide ( 2 hours, vehicle $13 \pm 2 \%$ versus AEA $36 \pm 6 \%$ relaxation, $n=10, P<.01$, Figure $5(\mathrm{a}))$,

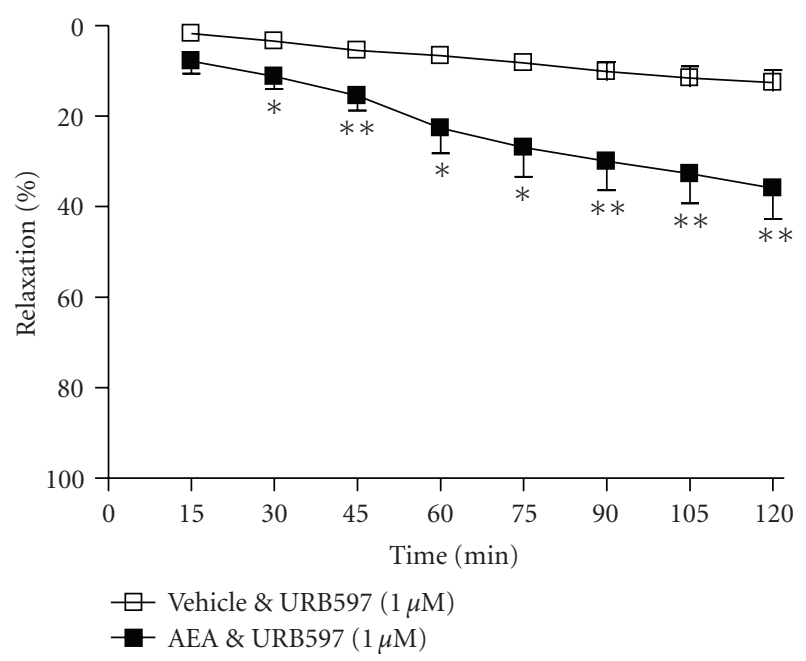

(a)

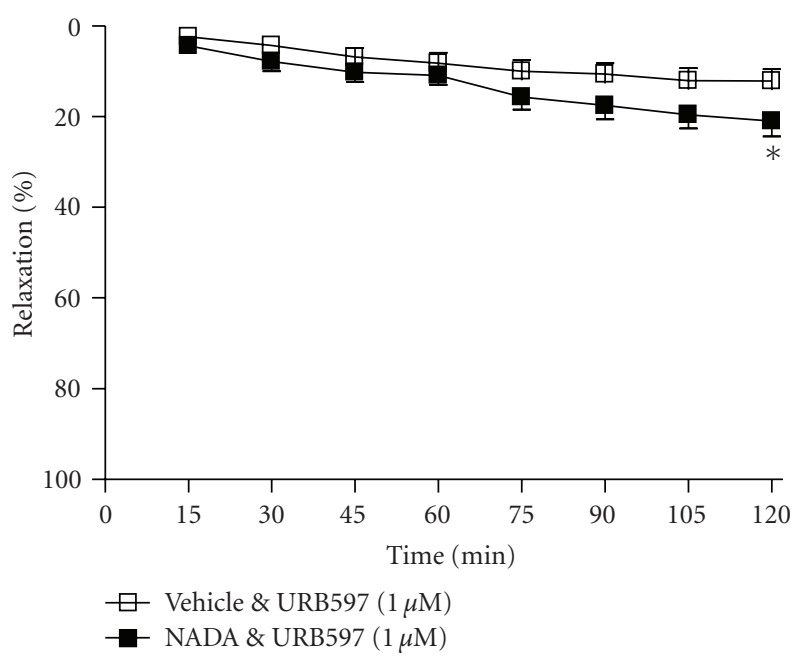

(b)

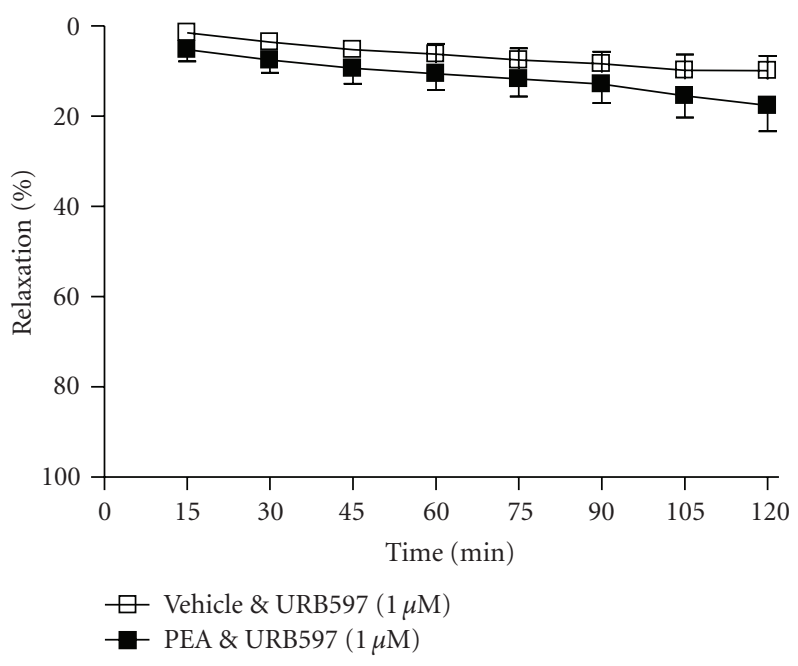

(c)

Figure 5: The effects of the FAAH inhibitor, URB597 $(1 \mu \mathrm{M})$ on vasorelaxation to (a) anandamide, (b) NADA, and (c) PEA. Data are given as means with error bars representing SEM. $\left({ }^{*} P<.05\right.$, ${ }^{* *} P<.01$, Student's $t$-test). 
and did not alter the vascular response to PEA (2 hours, vehicle $10 \pm 2 \%$ versus PEA $18 \pm 4 \%$ relaxation, $n=$ 7, nonsignificant, Figure 5(c)). URB597 did inhibit the vasorelaxant response to NADA such that NADA-treated and vehicle-treated arteries were significantly different at 2 hours only ( 2 hours, vehicle $12 \pm 2 \%$ versus NADA $21 \pm 3 \%$ relaxation, $n=9, P<.05$, Figure 5(b)).

\section{Discussion}

In the present study, we have examined whether endocannabinoids cause time-dependent, PPAR $\gamma$-mediated vascular effects as previously shown for the phytocannabinoid, THC $[13,19]$. In these studies, we demonstrate for the first time that the endocannabinoids anandamide and NADA cause $\operatorname{PPAR} \gamma$-mediated, time-dependent vasorelaxation of rat aortae, which is dependent on de novo protein synthesis, nitric oxide production and superoxide dismutase activity. These are similar mechanisms to those found to underlie the vasorelaxant effects of the PPAR $\gamma$ agonists, rosiglitazone [26], and THC [13].

On the basis that PPAR $y$ agonists cause time-dependent vasorelaxation of isolated aortae $[13,26]$, and that endocannabinoids activate $\operatorname{PPAR} \gamma \quad[14-18]$, we investigated whether endocannabinoids produce time-dependent vasorelaxation. The endocannabinoids chosen were anandamide and NADA, both previously demonstrated to activate PPAR $\gamma$ [14, 16-18], and PEA, which activates PPAR $\alpha$ but not PPAR $\gamma$ [10]. We found that, like rosiglitazone and THC, anandamide and NADA produced a slowly developing decrease in tone of precontracted aortae that was significantly greater than that seen in vehicle-treated segments of the same artery. The vascular response to anandamide and NADA was inhibited by the PPAR $y$ antagonist, GW9662, and by inhibition of de novo protein synthesis. In contrast, PEA did not cause vasorelaxation of the rat aorta. This is in agreement with our previous finding that the PPAR $\alpha$ ligand, bezafibrate, does not cause time-dependent vasorelaxation of isolated aortae [13]. These results demonstrate that $\operatorname{PPAR} \gamma$-, but not PPAR $\alpha$-active endocannabinoids cause time-dependent vascular effects.

Some of the vasorelaxant effects of cannabinoids are due to activation of other target sites such as the $\mathrm{CB}_{1}$ or $\mathrm{CB}_{2}$ receptor [27], and we explored whether the vasorelaxant response to endocannabinoids might be partially mediated by any of these. We found that neither the $\mathrm{CB}_{1}$ nor $\mathrm{CB}_{2}$ receptor antagonists had any significant effect on vasorelaxation to anandamide. However, vasorelaxation to NADA was inhibited by the $\mathrm{CB}_{1}$ receptor antagonist, $\mathrm{AM} 251$. It is possible, therefore, that NADA may activate cannabinoid receptors at the cell surface, initiating intracellular signalling that may lead to PPAR $y$ activation. For example, it has been shown that statins activate PPARs through activation of extracellular signal-regulated kinase (ERK) $1 / 2$ and p38 mitogen-activated protein kinase (MAPK) [28]. Both of these pathways can be activated by cannabinoid receptor activation $[29,30]$.

Further analysis of the time-dependent vasorelaxant effects of anandamide and NADA showed that these responses are partially endothelium-dependent and NOdependent, as previously demonstrated for rosiglitazone and THC $[13,26]$. We have also previously demonstrated that the PPAR $\gamma$-mediated vascular effects of cannabinoids are due to increases in SOD activity [13, 19]. Similarly, in the present study, the time-dependent effects of anandamide and NADA were abolished in the presence of a SOD inhibitor, DETCA, suggesting the vasorelaxant effects of anandamide and NADA are mediated by upregulation of SOD, preventing NO of being scavenged by endogenous superoxides. This is in agreement with other work showing PPAR $\gamma$ ligands cause the induction of $\mathrm{Cu} / \mathrm{Zn}-\mathrm{SOD}$ [20], and with numerous studies that have shown that PPAR $\gamma$ ligands increase NO production and bioavailability in vitro and in vivo [31-34].

There are several potential mechanisms by which cannabinoids can activate PPAR $y$ including direct binding, metabolism to other compounds that activate PPARs, or via intracellular signalling cascades. To establish whether endocannabinoids are metabolised into PPAR $\gamma$-active compounds, we performed some experiments in the presence of the FAAH inhibitor, URB597. The vasorelaxant effects of anandamide were not affected by URB597, which is consistent with previous studies showing that anandamide directly binds to PPAR $\gamma[16,17]$. It also suggests that prolonging the effects of anandamide by preventing its breakdown does not enhance the PPAR $y$-mediated vasorelaxant response. By contrast, the vasorelaxant effects of NADA were inhibited by URB597, suggesting that it is the conversion of this compound to PPAR $\gamma$-active metabolites that mediate the effects of NADA. There are no data presently available demonstrating a direct interaction between NADA and the PPAR $y$ ligand binding domain.

In summary, these data provide evidence for the first time that the endocannabinoids anandamide and NADA, but not the related acylethanolamide PEA, activate PPAR $\gamma$ in the vasculature, leading to $\mathrm{NO}$-dependent vasorelaxation. PPAR $y$ agonists have a number of positive cardiovascular effects, which include increased availability of $\mathrm{NO}$, in vivo reductions in blood pressure and attenuation of atherosclerosis [35-37]. Similarly, endocannabinoids have a number of beneficial effects on the cardiovascular system such as cardiac protection [38-40], benefits in hypertension [41, 42], and potential benefits in atherosclerosis [43]. PPAR $\gamma$ activation by some endocannabinoids may represent a novel mechanism by which they are involved in the regulation of the cardiovascular system.

\section{Acknowledgments}

The first author was previously supported by a Leverhulme Trust Early Career Fellowship. The authors would like to thank Dr. Richard Roberts for the use of a myograph.

\section{References}

[1] J. Janke, M. Schupp, S. Engeli, et al., "Angiotensin type 1 receptor antagonists induce human in-vitro adipogenesis through peroxisome proliferator-activated receptor- $\gamma$ activation," Journal of Hypertension, vol. 24, no. 9, pp. 1809-1816, 2006. 
[2] M. Jasińska, J. Owczarek, and D. Orszulak-Michalak, "Statins: a new insight into their mechanisms of action and consequent pleiotropic effects," Pharmacological Reports, vol. 59, no. 5, pp. 483-499, 2007.

[3] M. Schupp, J. C. Curtin, R. J. Kim, A. N. Billin, and M. A. Lazar, "A widely used retinoic acid receptor antagonist induces peroxisome proliferator-activated receptor- $\gamma$ activity," Molecular Pharmacology, vol. 71, no. 5, pp. 1251-1257, 2007.

[4] N. K. Salam, T. H.-W. Huang, B. P. Kota, M. S. Kim, Y. Li, and D. E. Hibbs, "Novel PPAR-gamma agonists identified from a natural product library: a virtual screening, induced-fit docking and biological assay study," Chemical Biology \& Drug Design, vol. 71, no. 1, pp. 57-70, 2008.

[5] K. Kuroyanagi, M.-S. Kang, T. Goto, et al., "Citrus auraptene acts as an agonist for PPARs and enhances adiponectin production and MCP-1 reduction in 3T3-L1 adipocytes," Biochemical and Biophysical Research Communications, vol. 366, no. 1, pp. 219-225, 2008.

[6] S. E. O'Sullivan, "Cannabinoids go nuclear: evidence for activation of peroxisome proliferator-activated receptors," British Journal of Pharmacology, vol. 152, no. 5, pp. 576-582, 2007.

[7] K. R. Kozak, R. A. Gupta, J. S. Moody, et al., "15-lipoxygenase metabolism of 2-arachidonylglycerol: generation of a peroxisome proliferator-activated receptor $\alpha$ agonist," The Journal of Biological Chemistry, vol. 277, no. 26, pp. 23278-23286, 2002.

[8] J. Fu, S. Gaetani, F. Oveisi, et al., "Oleylethanolamide regulates feeding and body weight through activation of the nuclear receptor PPAR- $\alpha$, Nature, vol. 425, no. 6953, pp. 90-93, 2003.

[9] M. Guzmán, J. Lo Verme, J. Fu, F. Oveisi, C. Blázquez, and D. Piomelli, "Oleoylethanolamide stimulates lipolysis by activating the nuclear receptor peroxisome proliferatoractivated receptor $\alpha$ (PPAR- $\alpha)$," The Journal of Biological Chemistry, vol. 279, no. 27, pp. 27849-27854, 2004.

[10] J. Lo Verme, J. Fu, G. Astarita, et al., "The nuclear receptor peroxisome proliferator-activated receptor- $\alpha$ mediates the antiinflammatory actions of palmitoylethanolamide," Molecular Pharmacology, vol. 67, no. 1, pp. 15-19, 2005.

[11] Y. Sun, S. P. H. Alexander, D. A. Kendall, and A. J. Bennett, "Cannabinoids and PPAR $\alpha$ signalling," Biochemical Society Transactions, vol. 34, no. 6, pp. 1095-1097, 2006.

[12] J. Liu, H. Li, S. H. Burstein, R. B. Zurier, and J. D. Chen, "Activation and binding of peroxisome proliferator-activated receptor $\gamma$ by synthetic cannabinoid ajulemic acid," Molecular Pharmacology, vol. 63, no. 5, pp. 983-992, 2003.

[13] S. E. O’Sullivan, E. J. Tarling, A. J. Bennett, D. A. Kendall, and M. D. Randall, "Novel time-dependent vascular actions of $\Delta^{9}$ tetrahydrocannabinol mediated by peroxisome proliferatoractivated receptor gamma," Biochemical and Biophysical Research Communications, vol. 337, no. 3, pp. 824-831, 2005.

[14] C. E. Rockwell and N. E. Kaminski, "A cyclooxygenase metabolite of anandamide causes inhibition of interleukin-2 secretion in murine splenocytes," Journal of Pharmacology and Experimental Therapeutics, vol. 311, no. 2, pp. 683-690, 2004.

[15] C. E. Rockwell, N. T. Snider, J. T. Thompson, J. P. Vanden Heuvel, and N. E. Kaminski, "Interleukin-2 suppression by 2 -arachidonyl glycerol is mediated through peroxisome proliferator-activated receptor $\gamma$ independently of cannabinoid receptors 1 and 2," Molecular Pharmacology, vol. 70, no. 1, pp. 101-111, 2006.

[16] M. Bouaboula, S. Hilairet, J. Marchand, L. Fajas, G. Le Fur, and P. Casellas, "Anandamide induced PPAR $y$ transcriptional activation and 3T3-L1 preadipocyte differentiation," European Journal of Pharmacology, vol. 517, no. 3, pp. 174-181, 2005.
[17] V. Gasperi, F. Fezza, N. Pasquariello, et al., "Endocannabinoids in adipocytes during differentiation and their role in glucose uptake," Cellular and Molecular Life Sciences, vol. 64, no. 2, pp. 219-229, 2007.

[18] S. E. O’Sullivan, A. J. Bennett, D. A. Kendall, and M. D. Randall, "Cannabinoids and peroxisome proliferatoractivated receptor gamma (PPAR $\gamma)$," in Proceedings of the International Cannabinoid Research Society (ICRS '06), p. 59, Tihany, Hungary, June 2006.

[19] S. E. O'Sullivan, D. A. Kendall, and M. D. Randall, "Further characterization of the time-dependent vascular effects of $\Delta^{9}$ tetrahydrocannabinol," Journal of Pharmacology and Experimental Therapeutics, vol. 317, no. 1, pp. 428-438, 2006.

[20] J. Hwang, D. J. Kleinhenz, B. Lassègue, K. K. Griendling, S. Dikalov, and C. M. Hart, "Peroxisome proliferator-activated receptor- $\gamma$ ligands regulate endothelial membrane superoxide production," American Journal of Physiology, vol. 288, no. 4, pp. C899-C905, 2005.

[21] P. M. Zygmunt, J. Petersson, D. A. Andersson, et al., "Vanilloid receptors on sensory nerves mediate the vasodilator action of anandamide," Nature, vol. 400, no. 6743, pp. 452-457, 1999.

[22] D. Harris, A. I. McCulloch, D. A. Kendall, and M. D. Randall, "Characterization of vasorelaxant responses to anandamide in the rat mesenteric arterial bed," Journal of Physiology, vol. 539, no. 3, pp. 893-902, 2002.

[23] S. E. O'Sullivan, D. A. Kendall, and M. D. Randall, "Vascular effects of $\Delta^{9}$-tetrahydrocannabinol (THC), anandamide and $\mathrm{N}$-arachidonoyldopamine (NADA) in the rat isolated aorta," European Journal of Pharmacology, vol. 507, no. 1-3, pp. 211221, 2005.

[24] L. Offertáler, F.-M. Mo, S. Bátkai, et al., "Selective ligands and cellular effectors of a G protein-coupled endothelial cannabinoid receptor," Molecular Pharmacology, vol. 63, no. 3, pp. 699-705, 2003.

[25] P. M. Hoi and C. R. Hiley, "Vasorelaxant effects of oleamide in rat small mesenteric artery indicate action at a novel cannabinoid receptor," British Journal of Pharmacology, vol. 147, no. 5, pp. 560-568, 2006.

[26] S. E. Cunnane, Y. Y. Chan, and M. D. Randall, "Rosiglitazoneinduced vasorelaxation in the rat aorta," Proceedings of the British Pharmacological Society, vol. 2, no. 2, abstract 096P, 2004.

[27] M. D. Randall, D. A. Kendall, and S. E. O'Sullivan, "The complexities of the cardiovascular actions of cannabinoids," British Journal of Pharmacology, vol. 142, no. 1, pp. 20-26, 2004.

[28] M. Yano, T. Matsumura, T. Senokuchi, et al., "Statins activate peroxisome proliferator-activated receptor $\gamma$ through extracellular signal-regulated kinase $1 / 2$ and p38 mitogen-activated protein kinase-dependent cyclooxygenase-2 expression in macrophages," Circulation Research, vol. 100, no. 10, pp. 14421451, 2007.

[29] B. L. Upham, A. M. Rummel, J. M. Carbone, et al., "Cannabinoids inhibit gap junctional intercellular communication and activate ERK in a rat liver epithelial cell line," International Journal of Cancer, vol. 104, no. 1, pp. 12-18, 2003.

[30] D. G. Demuth and A. Molleman, "Cannabinoid signalling," Life Sciences, vol. 78, no. 6, pp. 549-563, 2006.

[31] Z. Bagi, A. Koller, and G. Kaley, "PPAR $y$ activation, by reducing oxidative stress, increases NO bioavailability in coronary arterioles of mice with Type 2 diabetes," American Journal of Physiology, vol. 286, no. 2, pp. H742-H748, 2004.

[32] D.-H. Cho, Y. J. Choi, S. A. Jo, and I. Jo, "Nitric oxide production and regulation of endothelial nitric-oxide synthase 
phosphorylation by prolonged treatment with troglitazone: evidence for involvement of peroxisome proliferator-activated receptor (PPAR) $\gamma$-dependent and PPAR $\gamma$-independent signaling pathways," The Journal of Biological Chemistry, vol. 279, no. 4, pp. 2499-2506, 2004.

[33] H. Y. Ling, S. D. Feng, S. H. Zhou, B. X. Wang, X. Q. Liu, and B. $\mathrm{Hu}$, "Effects of rosiglitazone on aortic function in rats with insulin resistant-hypertension," Sheng Li Xue Bao, vol. 57, no. 2, pp. 125-131, 2005.

[34] J. B. Majithiya, A. N. Paramar, and R. Balaraman, "Pioglitazone, a PPAR $\gamma$ agonist, restores endothelial function in aorta of streptozotocin-induced diabetic rats," Cardiovascular Research, vol. 66, no. 1, pp. 150-161, 2005.

[35] D. Bishop-Bailey, "Peroxisome proliferator-activated receptors in the cardiovascular system," British Journal of Pharmacology, vol. 129, no. 5, pp. 823-834, 2000.

[36] W. A. Hsueh and D. Bruemmer, "Peroxisome proliferatoractivated receptor $\gamma$ : implications for cardiovascular disease," Hypertension, vol. 43, no. 2, pp. 297-305, 2004.

[37] S. Z. Duan, M. G. Usher, and R. M. Mortensen, "Peroxisome proliferator-activated receptor- $\gamma$-mediated effects in the vasculature," Circulation Research, vol. 102, no. 3, pp. 283-294, 2008.

[38] N. J. Underdown, C. R. Hiley, and W. R. Ford, "Anandamide reduces infarct size in rat isolated hearts subjected to ischaemia-reperfusion by a novel cannabinoid mechanism," British Journal of Pharmacology, vol. 146, no. 6, pp. 809-816, 2005.

[39] D. Lamontagne, P. Lépicier, C. Lagneux, and J. F. Bouchard, "The endogenous cardiac cannabinoid system: a new protective mechanism against myocardial ischemia," Archives des Maladies du Coeur et des Vaisseaux, vol. 99, no. 3, pp. 242-246, 2006.

[40] P. Pacher and G. Haskó, "Endocannabinoids and cannabinoid receptors in ischaemia-reperfusion injury and preconditioning," British Journal of Pharmacology, vol. 153, no. 2, pp. 252262, 2008.

[41] S. Bátkai, P. Pacher, D. Osei-Hyiaman, et al., "Endocannabinoids acting at cannabinoid-1 receptors regulate cardiovascular function in hypertension," Circulation, vol. 110, no. 14, pp. 1996-2002, 2004.

[42] R. Sarzani, "Endocannabinoids, blood pressure and the human heart," Journal of Neuroendocrinology, vol. 20, supplement 1, pp. 58-62, 2008.

[43] F. Mach and S. Steffens, "The role of the endocannabinoid system in atherosclerosis," Journal of Neuroendocrinology, vol. 20 , supplement 1, pp. 53-57, 2008. 


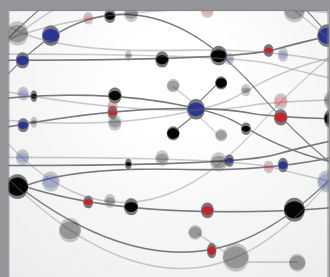

The Scientific World Journal
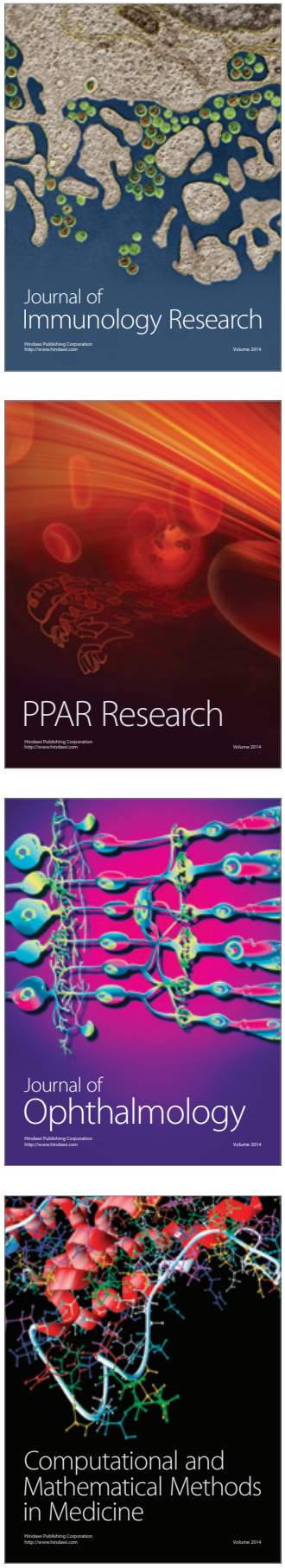

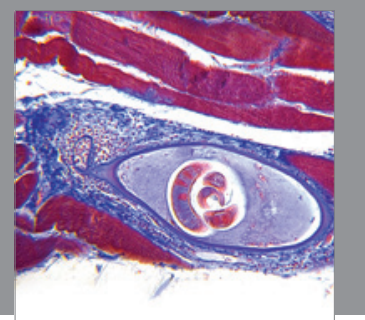

Gastroenterology

Research and Practice
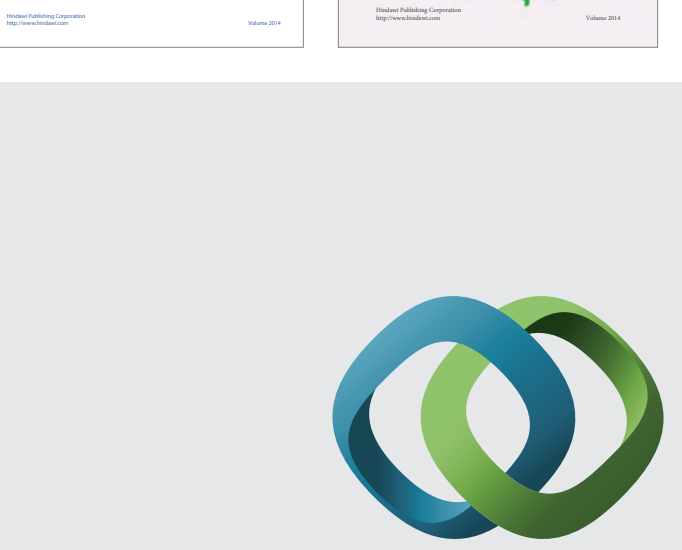

\section{Hindawi}

Submit your manuscripts at

http://www.hindawi.com
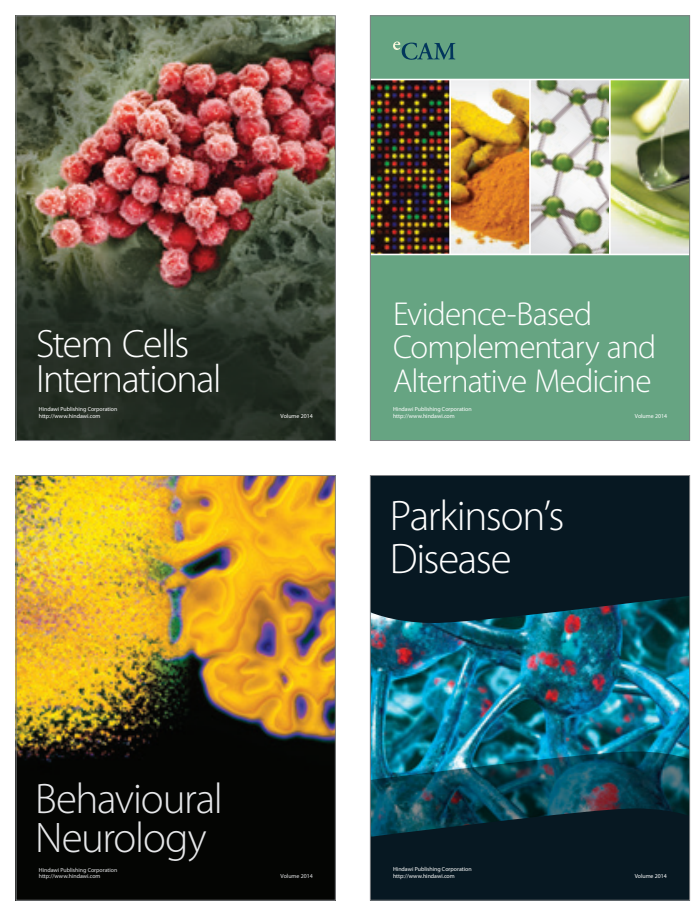

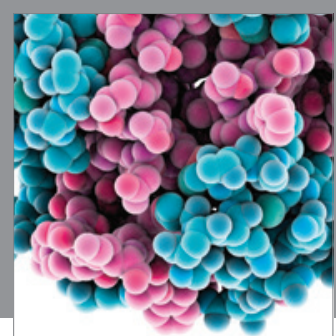

Journal of
Diabetes Research

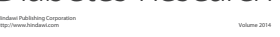

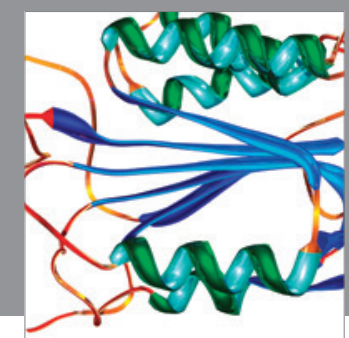

Disease Markers
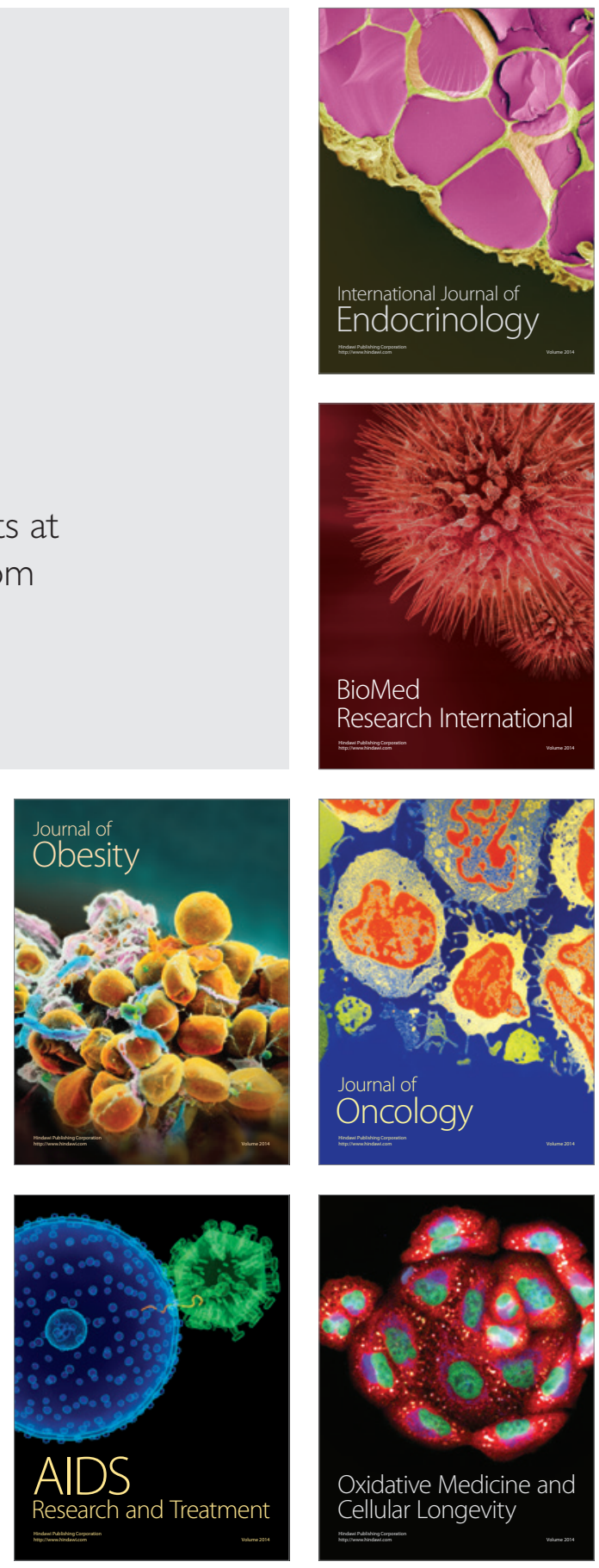